\title{
Neutrophiles: Acid Challenge and Comparison with Acidophiles
}

\author{
$P$ Jain, S Sinha
}

\section{Citation}

P Jain, S Sinha. Neutrophiles: Acid Challenge and Comparison with Acidophiles. The Internet Journal of Microbiology. 2008 Volume 7 Number 1.

DOI: $\underline{10.5580 / 1 \mathrm{ee} 7}$

\begin{abstract}
When neutrophiles like Escherichia coli are exposed to low $\mathrm{pH}$ environments mechanisms are required, within the cell, to alleviate the effects of lowered cytoplasmic $\mathrm{pH}$. They do undergo acid adaptation wherein there is an induction of glutamate decarboxylases, arginine decarboxylases and RpoS-dependent oxidative systems etc. After rapid acid treatment neutrophiles show a change in the expression of three different classes of genes. This review discusses the mechanisms adopted by neutrophiles to be able to survive and grow in the extreme acid conditions and a compares these mechanisms with those that are exclusively present in acidophiles.
\end{abstract}

\section{INTRODUCTION}

Most of the microorganisms are neutrophiles since they survive within the $\mathrm{pH}$ range of 5 to 8.5 and exhibit maximum growth rate at neutral or near neutral $\mathrm{pH}$. The ability of neutrophilic bacteria to survive under acidic condition is essential for successful colonization in the mammalian host because low $\mathrm{pH}$ environment leads to cytoplasmic acidification in microorganism. The acidic condition causes growth arrest and bacterial death due to change in structure of macromolecules, disruption of enzymatic reaction and membrane potential (Jeong et al. 2008). To counter such an effect and maintain $\mathrm{pH}$ homeostasis these bacteria have developed several mechanisms, which are:

1. A cellular envelope modification to reduce ionic permeability or decrease membrane fluidity (Benjamin \& Datta, 1995; Dilworth \& Glenn, 1999).

2. Induction of DNA repair machinery and chaperone proteins, which results in major change in gene expression and overexpression of some genes (Bearson et al. 1997).

3. The development of ionic pumping system and proton extrusion/uptake system (Dilworth and Glenn 1999).

4. Increasing external $\mathrm{pH}$ indirectly, that involves the decarboxylase activity of glutamate, arginine and lysine (Hommais et al. 2004).
The $\Delta \mathrm{pH}$ across the cytoplasmic membrane, which is linked to cellular bioenergetics and metabolism of the body, is major supplier of the proton motive force (PMF). According to Mitchell's chemiosmotic hypothesis, the transmembrane electrochemical gradient of protons plays a central role in energy transduction and transport processes in bacteria. These organisms contain membrane-bound proton pumps that generate a transmembrane proton motive force composed of a transmembrane electrical potential and a transmembrane $\mathrm{pH}$ gradient. So, if the influx of protons into the cytoplasm through the membrane bound $\mathrm{FF}_{1}$ ATPase to produce ATP, is left unrestricted, it will rapidly destroy the internal $\mathrm{pH}$ away from neutral or near neutral (Michels and Bakker 1985). As most of the proteins and enzymes are functional at neutral or near neutral $\mathrm{pH}$ their functions may be impaired by the disturbance in cellular $\mathrm{pH}$ or by protonation.

The interference caused by these free intracellular protons impairs processes such as transcription, protein synthesis and enzyme activities (Madshus 1988). Hence, homeostasis of cellular $\mathrm{pH}$ is essential.

The high acidity of stomach and the volatile fatty acids which are produced by fermentation in the intestine cause the development of a low $\mathrm{pH}$ environment. Because of its overall and specific consequence on protein stability and metabolic reaction, intracellular $\mathrm{pH}$ in microorganism is 
closely monitored to neutral or near neutral $\mathrm{pH}$ (Hommais et al. 2004). At extremely low $\mathrm{pH}$ the survival and growth of the stationary phase cells is termed as 'acid resistance' or 'acid tolerance'. There occur morphological and genetic changes as the neutrophilic cells enter the stationary phase, stopping to grow, to prolong the survival and increase resistance to various types of stress conditions (Small et al. 1994). During protein synthesis the buffering capacity of cytoplasm, low proton permeability and extrusion of protons from the cytoplasm by a membrane bound proton pump are other mechanisms which play important roles in acid resistance (Tosun and Gonul 2005).

Bacteria can also sense and respond to environmental changes through the use of two-component signal transduction systems by a coordinated regulation of gene expression. In bacteria the two-component system, which consists of a sensor kinase, and its cognate response regulator are some of the major mechanisms of signal transduction leading to specific gene expression (Hoch 2000; West and Stock 2001; Masunda and church 2003). Most of the neutrophiles show $\mathrm{pH}$ dependant gene expression during logarithmic growth in acid (pH 5-6) which involves regulation of gene expression and protein synthesis, as well as post-translational modification and regulation of protein function (Kanna et al. 2008).

Under mild acid shock conditions bacteria change the cell surface hydrophobicity and also induce a change in the composition of outer membrane proteins to maintain $\mathrm{pH}$ homeostasis. In most bacteria a low $\mathrm{pH}$ condition induces mechanisms that are involved in the synthesis of degradative amino acid decarboxylases (Dilworth and Glenn 1999). Based on acid tolerance there are four cellular levels of tolerance in bacteria, viz. log phase cells, acid adapted log phase cells, stationary phase cells and acid adapted stationary phase cells. The specific proteins encoded by specific genes are called as acid shock proteins. These proteins are required for acid adaptation of $\log$ and stationary phase cells (Foster 2001).

Acid adaptation or inducible acid tolerance means that the microorganism, after exposure to acidic condition, shows an increased resistance to the environmental stress. The gradual increase in acidic condition allows the microorganism to induce acid resistance (habituation to acid) followed by which the habituated organism can survive subsequent exposures to low $\mathrm{pH}$ conditions which prove to be hazardous to non-habituated cells (Goodson and Rowbury 1989). Habituation in most of the bacteria involves a phenotypic change in the organisms which gain acid resistance after an exposure to low $\mathrm{pH}$ for a short time. Such development of acid resistance is dependent on the protein synthesis machinery and the number of proteins that are induced at low pH (Raja et al. 1991). The cells which are acid shocked increase their acid tolerance at $\mathrm{pH} 2.5$ or 3 but in the cells which have undergone acid adaptation acid tolerance is not induced at $\mathrm{pH} 2.5$ or 3 . In the case of acid shocked cells the bacteria which are exposed to acid at $\mathrm{pH} 4.5$ for 2 hours have the highest acid tolerance (Tosun and Gonul 2005).

In natural environment, Escherichia coli is exposed to shortchain fatty acids, such as acetic acid or propionic acid, which can be utilized as carbon source but which inhibit growth at higher concentrations. The ability of neutrophilic bacteria to survive at low $\mathrm{pH}$ is also affected by environmental factors such as composition of the media, growth phase and exposure to short chain fatty acids such as acetate, propionate and butyrate at neutral or nearly neutral $\mathrm{pH}$ (Arnold et al. 2001). The uncoupling effects of these short chain fatty acids on transmembrane chemical potential in the plasma membrane of bacteria create the toxicity in the bacteria. These short chain fatty acids diffuse across the plasma membrane in their neutral form and on entering into the cytoplasm the anionic form of these short chain fatty acid is generated, releasing proton inside the cytoplasm. Thus, the proton which is released inside the cytoplasm decreases the transmembrane proton gradient or proton motive force and interferes with the well-organized energy metabolism that is generation of energy through oxidative phosphorylation (Polen et al. 2003). The effects of these short chain fatty acids upon upregulation of genes and survival also differ with the different types of carbon sources (Lasko et al. 2000).

\section{ACID INDUCED DECARBOXYLASE ACTIVITY:}

These systems provide acid resistance by consuming intracellular protons via the amino acid decarboxylation reaction and also by gradual alkalinization of the medium. The decarboxylases consume an intracellular proton while removing $\mathrm{CO}_{2}$ from their amino acid substrates.

Decarboxylation products are then expelled by specific antiporters in exchange for new substrate.

The decarboxylase activities include the activities of glutamate, arginine and lysine decarboxylases, which enhance growth under acid conditions by neutralizing the medium (Dilworth \& Glenn 1999; Small and Waterman 1998). The decarboxylation products following the action of 
decarboxylases are 4 -amino butyric acid (GABA), agmatine and cadaverine, which are expelled from the cell by systemspecific anti-porters (GadC for GABA, AdiC for agmatine and $\mathrm{CadB}$ for cadaverine) in exchange for new substrates (Gong et al. 2003; Iyer et al. 2003). Thus, these systems protect the cell from acid stress by consuming intracellular protons during each decarboxylation reaction. The removal off intracellular protons is used to enhance $\mathrm{pH}$ homeostasis and to allow the cell to maintain a neutral or near neutral internal $\mathrm{pH}$.

\section{ACID INDUCED ARGININE DEPENDANT DECARBOXYLASE ACTIVITY:}

Arginine-dependent system is composed of the acidinducible arginine decarboxylase AdiA and the AdiC. AdiA and AdiC are membrane antiporter of major facilitator superfamily (MFS), also belongs to the subfamily of decarboxylation-driven "virtual proton pumps". AdiC, an Arg-Agm exchanger, exchanges extracellular arginine for the intracellular end product of decarboxylation product 1 amino-4-guanidino-n-butane commonly known as agmatine. This reaction consumes a proton and throws it outside the cytoplasm as virtual proton which results in the maintaince of $\mathrm{pH}$ inside the cells. Thus, the cells can easily survive the acidic environment (Fang et al. 2007).

\section{ACID INDUCED GLUTAMATE DEPENDANT DECARBOXYLASE ACTIVITY:}

This acid induced decarboxylase system consists of three genes, i.e., gadA and gadB, which encode a highly homologous glutamate decarboxylase isoform. A third gene, gadC, encodes a putative glutamate: GABA antiporter. The two genes, gadA and gadB are located at a distance of 2,100 $\mathrm{kb}$ and differ by only 5 amino acid residues (De-Biase et al. 1996). The two isoforms of glutamate decarboxylase, viz. GadA and GadB, convert intracellular glutamate to [-amino butyric acid and in the process consume a proton.

Simultaneously GadC exports GABA, the end product out of the cell, along with the simultaneous import of more glutamate into the cell as substrate. These conversions change internal $\mathrm{pH}$ and electrical charge in ways that enable the cell to survive extreme acid stress conditions so far by maintaining the $\mathrm{pH}$ homeostasis (Richard and Foster 2004). The expression of gad at transcriptional level is controlled by an operon and a number of other factors, which differ depending upon the growth phase and environmental factor including H-NS, RpoS and CRP-cAMP (Castanie-Cornet and Foster 2001; De-Biase et al. 1999; Rowbury 1997; Rowland et al. 1984).
GadE is a central regulator involved in the regulation of several genes required in the regulation of $\mathrm{pH}$ homeostasis. Neutrophilic bacteria under high acidic conditions acquire increased acid resistance by overexpression of yhiE (renamed gadE), similar to overexpression of gadX, a known regulator of glutamate decarboxylase expression system. GadE has a potential helix-turn-helix DNA-binding motif, between amino acids 131 and 152 . GadE regulates target genes by binding to the promoter regions of these target $\operatorname{gadA}$ and gadB genes (hommais et al. 2004).

GadX protein, encoded by the gadX gene (known as yhiX), is located downstream to the gadA and is member of the AraC/XylS family of transcriptional regulators (Ma et al. 2002). Thus, both the gadA and gadB promoters are characterized by the presence of multiple sites of interaction with GadX but they differ considerably in the overall organization (number, position, size, and sequence) of binding sites, which reflects significant differences in the regulation of these genes by GadX (Tramonti et al. 2002).

GadX is a DNA-binding protein whose promoter sequence is the 67-bp region prior to the gadX transcription start site. GadX expression was positively correlated with both upregulation of gadA, gadBC genes and resistance to acidic $\mathrm{pH}$. This $\operatorname{gadX}$ binds to gadA and gadBC genes to different extents by recognizing the promoters of gadA and gadBC and GadX expression results in upregulation of target genes during exponential growth (hommais et al. 2001). GadX is a terminal component of the H-NS and RpoS dependent regulatory pathway and contains both RpoD and RpoS putative recognition sites which are responsible for gadA and gadBC transcriptional control (Tramonti et al. 2002).

Under oxidative conditions the nucleoid protein $\mathrm{H}-\mathrm{NS}$ is involved in the negative control of transcription of both gadA and gadBC gene, which takes place during the exponential growth phase by regulating the expression of GadW and GadX gene directly. The alternative sigma factor RpoS which is repressed by the cAMP receptor protein (CRP) increases its expression in acidic condition and is responsible for gad expression at the stationary phase. RpoS activates a gene located downstream of gadX, known as gadY, whose small-RNA (sRNA) product stabilizes gadX mRNA and the resulting increase in GadX expression (Opdyke et al. 2004)

Overexpression of gadX and gadE genes significantly induces the expression of genes that are involved in: 
1. Bacterial acid response (gadA, gadE).

2. Biosynthesis of bacterial membrane protein and lipids.

3. Biosynthesis of glutamate (gltD, glnH).

4. Other stress responses genes or genes encoding for chaperone proteins (hdeA, hdeB and $\mathrm{rfaG}$ ) (hommais et al. 2004).

Overexpression of gadX significantly induces the expression of 48 genes of H-NS regulon, several of them being acid responsive genes involved at low $\mathrm{pH}$. Some of these genes are the glutamate decarboxylase system $(\operatorname{gadA}, \operatorname{gadB}$, and gadC), the lysine decarboxylase system ( $\operatorname{cadA}, \operatorname{cadB})$, the regulator-encoding gene (gadW/yhiW) or other acid induced genes (hdeA, hdeB and hdeD). The hdeAB operon is located immediately downstream of hdeD and is transcribed in the opposite direction with the initiation of the hdeAB operon (Yoshida et al. 1993) HdeA and HdeB are periplasmic proteins, whereas HdeD is a membrane protein (Gajiwala and Burley 2000). HdeA's role in acid resistance is to prevent the aggregation of denatured periplasmic proteins at low pH (Masuda and Church 2003)

Gad X gene activates the expression of gene called as trmE because of its role in tRNA modification, encodes an Eralike GTPase that is required for gadA/BC expression and also activates GadE gene (Cabedo et al., 1999). TrmE (also known as MnmE) is a three-domain protein proposed to be a GTPase molecular switch. These GTPases achieve different conformations depending on whether they are bound to GTP or GDP (Gong et al. 2004). Integration host factor (IHF), H$\mathrm{NS}$ and $\mathrm{CysB}$ often influence $\mathrm{pH}$ responses, affecting either the DNA bending needed for transcription from some promoters (IHF and H-NS), supercoiling (possibly CysB) or activation of RNA polymerase (CysB) (Rowbury 1997).

\section{H-NS REGULATION:}

The histone-like protein H-NS influences a variety of cellular processes, such as replication, transcription and recombination, and is a major component of the bacterial nucleoid. This nucleoid protein H-NS is involved in the negative control (Yoshida et al. 1993). The mechanism underlying gene regulation by H-NS is either a change in DNA supercoiling or transcriptional silencing. The transcriptional silencing occurs through preferential binding to AT-rich curved DNA sequences which are found upstream of promoters of gad genes (Waterman and Small 2003). H-NS silencing of gene expression is relieved by environmental signals, such as changes in osmolarity, growth phase, low temperature, and $\mathrm{pH}$ (Atlung and Ingmer 1997).

\section{YDEO REGULATION:}

Overexpression of gadX induces the expression of several genes encoding regulatory proteins; one of them being is $\mathrm{YdeO}$ gene. YdeO gene is a member of the AraC/XylS transcriptional regulator family. A gene array studies of bacteria shows that overexpression of these regulators suggested a regulatory circuit in which the EvgSA, twocomponent regulatory system, activates expression of the AraC-like regulator ydeO which then activates acid resistance. Deletion of the ydeO structural gene results in decreased acid resistance caused by EvgA overexpression which shows bacterial response to an acidic environment (Ma et al. 2004).

\section{CHANGE IN MEMBRANE LIPID COMPOSITION:}

In most of the bacteria low $\mathrm{pH}$ condition induces a change in the composition of lipids and a decrease in membrane fluidity which may increase acid resistance. Membrane fluidity is important for cells because it affects membrane functions such as biochemical reactions, transport systems, and protein secretion. In general, membrane fluidity is affected by the ratio of unsaturated fatty acid to saturated fatty acids. The decrease in membrane fluidity under acidic growth conditions may be associated with changes in proton flux so that acid adapted cells do not allow protons to flow into the cell as easily as non adapted cells. Most of the shortchain fatty acids found in the lipid A component of the outer membrane do not contribute much to the fluidity of the membrane (Yuk and Marshall 2004). The fatty acids which are most influenced by the $\mathrm{pH}$ in most of the bacteria are palmitic (16:0), cis-vaccenic (18:107c), cyclohepta-decanoic (C17:0), and cyclononadecanoic (C19:0) acids. Acid adaptation increases the amounts of palmitic acid (C16:0) and decreases cis-vaccenic acid (C18:107c) in the membrane lipids in most of the bacteria during acidic condition (Brown et al. 1997).

\section{DNA REPAIR PATHWAY:}

DNA repair represents a major strategy for bacteria to stay on viable following passage through extreme $\mathrm{pH}$ conditions such as the gastric barrier. In bacterial cell the low $\mathrm{pH}$ condition damages chromosomal DNA as a result of selective depurination or by breakage in double stranded DNA. Such depurination causes the accumulation of unrepaired DNA and mismatch sequences, which lead to 
death of the cells. Therefore, DNA repair pathways are important for cell survival in low-pH conditions (Raja et al. 1991). DNA repair pathway includes repair mechanisms involving recA and uvrB, which also help in survival during extreme gastric acidity. These DNA repair processes may be the same or interconnected to different factors that lead to increased UV-resistance and increased repair of UVdamaged DNA in acid-habituated neutrophilic bacteria (Goodson and Rowbury 1989). The GroEL protein (molecular weight 62883) appears to combine with the DNA of the bacterium and protects the microorganism by either preventing DNA damage or by repairing the already damaged DNA after a short exposure to heat and, consequently, after mild stress of acid (Jan et al. 2001).

\section{DNA DAMAGE IS PREVENTED BY DPS BINDING:}

The most important protein that contributes to acid tolerance of E.coli is the DNA binding protein in starved cell (Dps) (Almiron et al. 1992). This Dps protein is expressed at low level during late exponential growth phase but becomes the most abundant protein in stationary-phase cells during acidic conditions (Jeong et al. 2008). The Dps protein protects the DNA by a mechanism of formation of spherical dodecamer complexes, similar to that by ferritin complex. This DNADps complex which is stable at low $\mathrm{pH}$, protects the DNA from the hydroxyl radicals formed during acid stress (Choi et al. 2000).

The low $\mathrm{pH}$ condition appears to build up the Dps-DNA association and bring back the DNA binding activity of heat denatured Dps. DNA is a common target of Dps protection inspite of the stress through physical association and appropriation of reactants that produce free radicals. The secondary structure of Dps protein retains or forms alpha helices at low $\mathrm{pH}$ condition. Dps protein also plays an important role in survival during other stress conditions including starvation, near-UV and gamma irradiation, thermal stress, metal toxicity and oxidative stress (Jeong et al. 2008). In some cases highly ordered nucleoprotein complexes are formed which is capable of altering gene expression patterns when Dps binds to DNA in acidic condition. Acid challenge of whole cells results in chromosomal DNA damage and this damage increases with more exposure time. However, Dps influences expression of other genes that protect or repair DNA or provide acid tolerance. Dps is a key component of the general stress protection system that is important in the survival of the bacteria in acidic condition (choi et al. 2000).

\section{INDUCIBLE ACID TOLERANCE SYSTEMS:}

A sublethal environmental acid stress ( $\mathrm{pH}$ 5.5-4.5) provides protection against subsequent exposure to a lethal stress $(\mathrm{pH}$ $<4.0$ ) by inducing an adaptive tolerance response in many bacteria, which is known as acid tolerance response (ATR) (Depentiene et al. 2005). At neutral pH or near neutral, high concentration of short chain fatty acids affect the expression of the general stress response genes at the transcriptiontranslation machineries. Genes, whose expression is altered by exposure to acetate, may be categorized into three types on the basic of their transcriptomic profiling.

Increase in the RNA level of the gene of flagellum and chemotaxis, which results in increase in swimming motility after acid adaptation.

Decrease in the expression of several genes which are involved in metabolism and uptake of carbon source.

Increase in the expression of genes of general stress response (Polen et al. 2003)

\section{ACETATE INDUCED ACID TOLERANCE:}

Acetate is transported into the cells and activated to acetyl coenzyme-A by acetyl-coA synthetase (encoded by acs gene). The expression of this enzyme increases in the presence of acetate and is regulated by cyclic AMP (cAMP) receptor protein and FNR as well as its activator, FadR. The acetyl-coA is further metabolised through the glyoxylate cycle and tricarboxylic acid cycle (Polen et al. 2003).

The other gene, whose expression is induced by exposure to acetate at neutral or near neutral $\mathrm{pH}$, codes for a protein that protects the cells against oxidative damage caused by superoxides and hydrogen peroxide. The cfa gene, which is an acetate induced gene, codes for a cyclopropane fatty acid synthase that is involved in the modification of the phospholipid profile by adding a methylene group across the carbon-carbon double bond of unsaturated fatty acids in the inner membrane (Grogan and Cronan 1997). The increased tolerance of stationary-phase cells for hydrogen peroxide challenge is due to the production of catalase. Bacteria possess three separate catalase genes (katG, katE, and katP). KatG is regulated by OxyR and mostly produced during log phase, while katE is primarily expressed in stationary phase. The regulation of the plasmid encoded (pO157) catalase (katP) has not been elucidated. The Kat E gene expression is regulated by RpoS which codes for catalase hydroperoxidase (Loewen et al. 1985). 
After addition of acetate there are many other genes whose relative expression level is decreased by at least $50 \%$ at the transcription-translation machinery. The majority of these genes encode a total of 41 ribosomal proteins, as well as the translation elongation factors EF-G, EF-Ts, and EF-Tu (Arnold et al. 2001).

\section{ROLE OF RPOS IN ACETATE INDUCED ACID TOLERANCE:}

In most of the neutrophiles the RpoS gene, which codes for the alternate sigma factor $\square \mathrm{s}$, is required for both stationary phase induced acid resistance and exponential phase induced acid resistance when the bacteria are grown at moderately low $\mathrm{pH}$ (Cheville et al. 1996).Among the genes whose expression is strongly induced by acetate is yhiW, which codes for Ara-c type regulating protein. This RpoS transcription factor may be involved in controlling some of the changes in gene expression in acidic condition. The rpoS gene regulates cfa transcription, which activates CFA synthase responsible for cyclo fatty acid and so rpoS is termed as a global stress regulon (Chang and Cronan 1999). Bacterial cells may activate this rpoS regulon in a low $\mathrm{pH}$ environment. rpoS regulon stimulates the conversion of monounsaturated fatty acids to their cyclopropane derivatives and thereby enhances the survival of bacterial cells exposed to low $\mathrm{pH}$, by decreasing the membrane fluidity. The rpoS gene is not involved in membrane lipid composition changes during adaptation to low $\mathrm{pH}$, even though rpoS can cause changes in cellular physiology and morphology in acidic condition. The genes whose expression is changed after acetate adaptation is RpoS dependent general stress response genes, viz. osmY, otsAB, poxB, dps, and hdeAB (Arnold et al. 2001). Overall the genes which are upregulated during acid condition are fimB, ygaC, yhcN,

yhjX, ymgABC and yodA. These genes which is upregulated, code for periplasmic chaperones, inner membrane and outer membrane proteins, acid stress proteins and the systems utilizing the proton gradient such as motility and chemotaxis proteins (Maurer et al. 2005).

\section{ACID TOLERANT MECHANISMS PRESENT SPECIFICALLY ONLY IN ACIDOPHILES}

Microorganisms that grow easily at extremely low $\mathrm{pH}$ or show growth at optimum $\mathrm{pH}$ below 3 are termed as acidophiles. Acidophiles have some distinctive structural and functional characteristics including a reversed membrane potential, highly impermeable cell membranes, a predominance of secondary transporters and a high proportion of iron protein that makes their survival more favorable under acidic condition

\section{MEMBRANE PERMEABILITY:}

The cell membrane of acidophilic bacteria is highly impermeable to protons, which restricts proton influx into the cytoplasm and thus maintains $\mathrm{pH}$ homeostasis. The membrane permeability shows that there is balance between proton influx through different types of uniporters, symporters, and proton influx in bioenergetics and the protons which are pumped out by the system. The low proton permeability of acidophiles is due to:

(a) The fixed nature of monolayer such that fracturing of these membranes does not lead to an opposing lipid bilayer and opposing polar head groups.

(b) A bulky isoprenoid core. This core contains three types of ether lipids, which are phospholipids, glycolipids, and phosphoglycolipids. The seven glycolipids have different combinations of the carbohydrates gulose (unusual sugar in nature), mannose, and glucose. The eight phosphoglycolipids, with two polar head groups contain glycerophosphate as the phosphoester moiety. All the ether lipids of the archaeal membrane lipids consist of C20, C25, and $\mathrm{C} 40$ hydrocarbons with zero to three cyclopentane rings (Shimada et al. 2002).

However, there are several structural variations in the isopranyl chains in different type of acidophiles that is halophiles have no tetraether lipids but have diether lipids, while thermophilic archaea have tetraether lipids with cyclopentane rings (Langworthy et al. 1986) and methanogens have both diether and tetraether lipids with no cyclopentane ring (Koga et al. 1993).

Another parameter of the membrane of the acidophiles is pore permeability and size, which is also important in maintaining $\mathrm{pH}$ homeostasis. The membrane channels reduce their pore size as the $\mathrm{pH}$ shifts from neutral to acidic. The membrane pore contains an identified L3 loop that selects the ions at the porin entrance on the basis of their size and charge. There is upregulation of outer membrane protein porin, which is $36-\mathrm{kDa}$ protein located in the membrane fraction that controls the size of the pore and ion selectivity (Amaro et al. 1991).

\section{DONNEN POTENTIAL BY CHEMIOSMOTIC GRADIENT:}

Amino acid-dependent acid resistance systems help the acidophile by converting the membrane potential inside from 
negative to positive, a well-known acidophile strategy used for survival in extreme acidic environments. Thus, changing the internal potential may be a more significant acid resistance strategy than maintaining a specific $\mathrm{pH}$ value. It involves the development of inside positive $\Delta \rrbracket$ which is opposite to inside negative $\Delta \square$ in neutrophiles. This is generated by donnan potential of positively charged molecules which inhibit the influx of protons using a chemiosmotic barrier against proton gradient (Baker-Austin and Dopson 2007).

\section{EXCESS PROTONS ARE ACTIVELY PUMPED OUT OF THE CELLS:}

To maintain $\mathrm{pH}$ homeostasis the acidophiles need to be able to remove excess protons from the cytoplasm by active proton pumping (i.e. using H+ ATPases, antiporters and symporters). Thus, by predominantly using secondary transporters, the proton motive force can be used for metabolic purposes or other structural work. The acidophiles are spontaneously capable of using the $\square \mathrm{pH}$ across the membrane to generate large amounts of ATP. Therefore, any protons that enter the cell through the $\mathrm{F} \mathrm{F}_{1}$ ATPase need to be balanced by extrusion during electron transport and reduction of molecular oxygen at the terminal oxidase of electron transport chain. In acidophiles the net $\mathrm{K}+$ uptake, during growth, plays an essential role in the conversion of $\Delta \square$ into $\Delta \mathrm{pH}$ and thereby helps in the development of positive internal membrane potential at low external $\mathrm{pH}$ (Michels and Bakker 1987).

\section{PROTON UNCOUPLING BY ORGANIC ACIDS:}

Most of the organic acids like acetic acid and lactic acid function as uncouplers of respiratory chain in acidophiles at low $\mathrm{pH}$. This is because, at low $\mathrm{pH}$, the acids diffuse into the cell in the protonated form followed by dissociation of a proton. Therefore, acidophiles have developed the mechanism of generation of energy and other useful products from the degradation $\neg$ of these above-mentioned organic and thus maintain the $\mathrm{pH}$ homeostasis (Alexander et al. 1987). Recently, the analysis of genomes of several acidophiles revealed the presence of genes encoding organic acid degradation pathways. These include genes encoding the enzymes propionyl-CoA synthase, two acetyl-CoA synthetases and lactate-2-monooxygenase that converts lactate to pyruvate. This suggested the active mechanism of maintaining $\mathrm{pH}$ homeostasis (Baker-Austin and Dopson 2007).

\section{INTRACELLULAR ENZYMES STABILIZED BY 'IRON RIVETS':}

Recent investigation of genome sequences of several acidophiles shows that enzymes of acidophiles are functional at much lower $\mathrm{pH}$ than the normal intracellular $\mathrm{pH}$ of 5.6. The low $\mathrm{pH}$ optimum activity of cytoplasmic proteins suggests that they need to be functional when the cells grow at such extreme $\mathrm{pH}$ values. It has also been found that most of the acidophile proteome contains a uniquely high proportion of iron proteins that contribute to the $\mathrm{pH}$ stability of enzymes at low $\mathrm{pH}$. Removal of the iron protein from these acidophiles leads to loss of secondary structure of the protein and, consequently its activity. This suggests that iron is crucial in maintaining the three dimensional structures of the proteins and functions as an 'iron rivet' - an ancient property that stabilizes proteins in acidic condition (BakerAustin and Dopson 2007).

\section{DNA AND PROTEIN DAMAGE CAUSED BY LOW PH CAN BE REPAIRED BY CHAPERONES:}

For cells to survive DNA repair is critical for the maintenance of genome integrity and replication fidelity in all acidophiles. DNA damage includes the presence of abnormal nucleotide (modified, fragmented and cross linked), single stranded and double stranded break, inter and intra stranded cross link, produced endogenously by a metabolic by-product or exogenously by an environmental condition. The presence of a large number of DNA and protein repair genes in acidophiles enables them to maintain pH homeostasis (Dopson et al. 2005).

\section{CONCLUSION}

Neutrophiles represent an ecologically and increasingly economically important group of microorganisms. The microorganisms that grow at low $\mathrm{pH}$ encounter a variety of problems including those associated with the biological system such as enzyme activity, stability of the molecules and specifically bioenergetics. This information has been unravelled from studies on $\mathrm{pH}$ homeostasis. There are three acid resistance systems present which include AR1, AR2 and AR3. AR1 includes the DNA binding protein like rpoS encoded global stress response, while AR2 and AR3 include glutamate and arginine amino acid decarboxylases. The progress of genetic, biochemical and structural approaches in neutrophile molecular biology will help to unravel many of the molecular mechanisms that enable life under extreme acid conditions. The development of functional genomics will allow us to gather further insight in to the genetics, biochemistry and physiology of these organisms. The 
genome sequences of the acidophiles and neutrophiles provide several hints of the mechanisms used for adaptation to such unfriendly environment, but most mechanisms remain unseen and await further analysis to be performed.

\section{References}

r-0. Alexander, B., S. Leach, and W.J. Ingledew. 1987. The relationship between chemiosmotic parameters and sensitivity to anions and organic acids in the acidophile Thiobacillus ferrooxidans. J. Gen. Microbiol. 133: 1171-1179.

r-1. Almiron, M., A.J. Link., D. Furlong. and R. Kolter. 1992. A novel DNA binding protein with regulatory and protective roles in starved Escherichia

coli. Genes Dev. 6: 2646-2654.

r-2. Amaro, A.M. D. Chamorro., M. Seeger., R. Arredondo., I. Peirano. and C.A. Jerez. 1991. Effect of external pH perturbations on in vivo protein synthesis by the acidophilic bacterium Thiobacillus ferrooxidans. J. Bacteriol. 173: 910-915.

r-3. Arnold, C. N., J. Mcelhanon., A. Lee., R. Leonhart. and D.A. Siegele. 2001. Global analysis of Escherichia coli gene expression during the acetate-induced acid tolerance response. J. Bacteriol. 183: 2178-2186.

r-4. Atlung, T., and H. Ingmer. 1997. H-NS: a modulator of environmentally regulated gene expression. Mol. Microbiol. 24: 7-17.

r-5. Baker-Austin, C. and M. Dopson. 2007. Life in acid: pH homeostasis in Acidophiles. Trends in Microbiol. 15: 165-171.

r-6. Benjamin, M.M. and A.R. Datta. 1995. Acid tolerance of enterohemorrhagic Escherichia coli. Appl. Environ.

Microbiol. 61: 1669-1672.

r-7. Bearson, S., B. Bearson. and J.W. Foster. 1997. Acid stress responses in enterobacteria. FEMS Microbiol. Lett. 147: 173-180.

r-8. Brown, J.L., T. Ross., T.A. Mcmeekin., and P.D. Nichols. 1997. Acid habituation of Escherichia coli and the potential role of cytoplasmic fatty acids in low $\mathrm{pH}$ tolerance. J. Food Microbiol. 37: 163-173.

r-9. Cabedo, H., F. Macian., M. Villarroya., J.C. Escudero., M. Martinez-Vicente., E. Knecht., and M.E. Armengod. 1999. The Escherichia coli trmE (mnmE) gene, involved in tRNA modification, codes for an evolutionarily conserved GTPase with unusual biochemical properties. EMBO J. 18: 7063-7076.

r-10. Castanie-Cornet, M.P. and J.W. Foster. 2001.

Escherichia coli acid resistance: cAMP receptor protein and a $20 \mathrm{bp}$ cis-acting sequence control $\mathrm{pH}$ and stationary phase expression of the gadA and gadBC glutamate decarboxylase genes. Microbiol. 147: 709-715.

r-11. Chang, Y.Y. and J.E. Cronan. 1999. Membrane cyclopropane fatty acid content is a major factor in acid resistance of Escherichia coli. Mol. Microbiol. 33: 249-259. r-12. Cheville, A.M., K.W. Arnold., C. Buchrieser., C.M. Cheng., and Kasper, C.W. 1996. rpoS regulation of acid, heat, and salt tolerance in Escherichia coli O157:H7. Appl. Environ. Microbiol. 62: 1822-1824.

r-13. Choi, Sang Ho., David J. Baumler., and C.W. Kasper. 2000. Contribution of dps to Acid Stress Tolerance and Oxidative Stress Tolerance in Escherichia coli O157:H7. Appl. Environ. Microbiol. 66: 3911-3916.

r-14. De-Biase, D., A. Tramonti., F. Bossa., \& P. Visca. 1999. The response to stationary-phase stress conditions in Escherichia coli: role and regulation of the glutamic acid decarboxylase system. Mol. Microbiol. 32: 1198-1211. r-15. De-Biase, D., A. Tramonti., R.A. John., and F. Bossa. 1996. Isolation, overexpression and biochemical characterization of the two isoforms of glutamic acid decarboxylase from Escherichia coli. Protein Expri. Purifi. 8: 430-438.

r-16. Depentiene, V., K. Supiedelis., E. Supiedeliene. 2005. Acid adaptation of Escherichia coli: a genetic study. Biologija. Nr1. 15-19.

r-17. Dilworth, M., and A. Glenn. 1999. Problems of adverse $\mathrm{pH}$ and bacterial strategies to combat it. In Bacterial Responses to $\mathrm{pH}$ (Novartis Foundation Symposium 221), 4-18. Edited by D. Chadwick \& G. Cardew. Chichester: Wiley.

r-18. Dopson, M., C. Baker-Austin., and Philip L. Bond. 2005. Analysis of differential protein expression during growth states of Ferroplasma strains and insights into electron transport for iron oxidation. Microbiol. 151: 4127-4137.

r-19. Fang, Y., L. Kolmakova-Partensky., and C. Miller. 2007. A Bacterial Arginine-Agmatine Exchange Transporter Involved in Extreme Acid Resistance. J. Biol. Chem. 282: 176-182.

r-20. Foster J.W. 2001. Acid stress responses of Salmonella and E. coli: Survival mechanisms, regulation, and implications for pathogenesis. Microbiol. 39: 89-94. r-21. Gajiwala, K.S. and S.K. Burley. 2000. HDEA, a periplasmic protein that supports acid resistance in pathogenic enteric bacteria. J. Mol. Biol. 295: 605-612. r-22. Gong, S., Z. MA., and J.W. Foster. 2004. The Era-like GTPase TrmE conditionally activates gadE and glutamatedependent acid resistance in Escherichia coli. Mol. Microbiol. 54: 948-961.

r-23. Gong, S., H. Richard., and J.W. Foster. 2003. YjdE (AdiC) is the arginine: agmatine antiporter essential for arginine-dependent acid resistance in Escherichia coli. J. Bacteriol. 185: 4402-4409.

r-24. Goodson, M. and R.J. Rowbury. 1989. Habituation to normally lethal acidity by prior growth of Escherichia coli at a sub-lethal acid pH value. Lett. Appl. Microbiol. 8: 77-79. r-25. Grogan, D.W. and J.E. Cronan. 1997. Cyclopropane ring formation in membrane lipids of bacteria. Microbiol. Mol. Biol. Rev. 61: 429-441.

r-26. Jan, G., Leverrier, P., Pichereau, V. and Boyaval P. 2001. Changes in Protein Synthesis and Morphology during Acid Adaptation of Propionibacterium freudenreichii Appl. Environ. Microbiol. 67: 2029-2036.

r-27. Hoch, J.A. 2000. Two-component and phosphorelay signal transduction. Curr. Opin. Microbiol. 3: 165-170. r-28. Hommais, F., E. Krin., C. Laurent-Winter., O. Soutourina., A. Malpertuy., JP. Le-Caer., A. Danchin., and P. Bertin. 2001. Large-scale monitoring of pleiotropic regulation of gene expression by the prokaryotic nucleoidassociated protein, H-NS. Mol Microbiol 40: 20-36. r-29. Ieyer, R., C. Willams., and C. Miller. 2003. Arginineagmatine antiporter in extreme acid resistance in Escherichia coli. J

Bacteriol. 185: 6556-6561.

r-30. Jeong, K.C., K.F. Hung., J. David. Baumler., Jeffrey J. Byrd., and W. Kasper. Charles. 2008. Acid stress damage of DNA is prevented by Dps binding in Escherichia coli O157:H7 BMC Microbiol. 8: 81:1-37.

r-31. Kannan, G., J.C. Wilks., D.M. Fitzgerald., B.D. Jones., S.S. Bondurant., and J.L. Sloczenski. 2008. Rapid acid treatment of Escherichia coli: transcriptomic response and recovery. BMC Microbiol. 8: 37-50.

r-32. Koga, Y., M. Nishihara., H. Morii., and M. AkagawaMatsushita. 1993. Ether polar lipids of methanogenic bacteria: structures, comparative aspects, and biosyntheses. 
Microbiol. Rev. 57: 164-182.

r-33. Langworthy, T.A., and J.L. Pond. 1986.

Archaebacterial ether lipids and chemotaxonomy. Syst.

Appl. Microbiol. 7: 253-257.

r-34. Lasko, D.R., N. Zamboni., and U. Saurer. 2000.

Bacterial response to acetate challenge: a comparison of tolerance among species. Appl. Microbiol. Biotechnol. 54: 243-247.

r-35. Loewen, P. C., J. Switala., and B.L. Triggs-Raine.

1985. Catalase HPI and HPII in Escherichia coli are induced independently. Arch. Biochem. Biophys. 243: 144-149. $\mathrm{r}-36$. Madshus, I.H. 1988. Regulation of intracellular $\mathrm{pH}$ in eukaryotic cells. Biochem. J. 250: 1-8.

r-37. Masuda, N., and, George M. Church. 2003. Regulatory network of acid resistance genes in Escherichia coli. Mol. Microbiol. 48: 699-712.

r-38. Maurer, L.M., E. Yohannes., S.S. Bondurant., M.Radmacher., and J.L. Slonczewski. 2005. pH regulates genes for flagellar motility, catabolism, and oxidative stress in Escherichia coli K-12. J. Bacteriol 187: 304-319.

r-39. Ma, Z., H. Richard., D.L. Tucker., T. Conway., and

J.W. Foster. 2002. Collaborative regulation of Escherichia coli glutamate-dependent acid resistance by two AraC-like regulators, GadX and GadW (YhiW). J. Bacteriol. 184: 7001-7012.

r-40. Ma, Zhuo., N. Masuda., and JOHN W. Foster. 2004. Characterization of EvgAS-YdeO-GadE Branched Regulatory Circuit Governing Glutamate-Dependent Acid Resistance in Escherichia coli. J. Bacteriol. 186: 7378-7389. r-41. Monika, M., and Evert, P. Bakker. 1985. Generation of a Large, Protonophore-Sensitive Proton Motive Force and $\mathrm{pH}$ Difference in the Acidophilic Bacteria Thermoplasma acidophilum and Bacillus acidocaldarius. J. Bacteriol. 161: 231-237.

r-42. Monika, M., and Evert P. Bakker. 1987. Low-Affinity Potassium Uptake System in Bacillus acidocaldarius. J.

Bacteriol. 169: 4335-4341.

r-43. Opdyke, J.A., J.G. Kang., and G. Storz. 2004. GadY, a small-RNA regulator of acid response genes in Escherichia coli. J. Bacteriol 186: 6698-6705.

r-44. Polen, T., D. Rittmann., V.F. Wendisch., and H. Sahm. 2003. DNA Microarray Analyses of the Long-Term Adaptive Response of Escherichia coli to Acetate and Propionate. Appl. Environ. Microbiol. 69: 1759-1774. r-45. Raja, N., M. Goodson., D.G. Smith., and R.J. Rowbury., 1991. Decreased DNA damage by acid and increased repair of acid-damaged acid-habituated Escherichia coli. J. appl. Bacteriol. 70: 507-511. r-46. Richard, H., and J.W. Foster. 2004. Glutamate and arginine- dependent acid resistance systems increase internal $\mathrm{pH}$ and reverse transmembrane potential. J. Bacteriol. 186: 6032-6041.

r-47. Rowbury, R.J. 1997. Regulatory components, including integration host factor, CysB, and H-NS, that influence $\mathrm{pH}$ responses in Escherichia coli. Lett. Appl. Microbiol 24: 319-328.

r-48. Rowland, G.C., P.M. Giffard., and I.R. Booth., 1984. Genetic studies of the phs locus of Escherichia coli, a mutation causing pleiotropic lesions in metabolism and $\mathrm{pH}$ homeostasis. FEBS Lett. 173: 295-300.

r-49. Shimada, H., N. Nemoto., Y. Shida., T. Oshima., and A.Yamagishi. 2002. Complete polar lipid composition of Thermoplasma acidophilum HO-62 determined by highperformance liquid chromatography with evaporative lightscattering detection. J. Bacteriol. 184: 556-563.

r-50. Small, P.L.C. and S.R. Waterman, 1998. Acid stress, anaerobiosis and gadCB: lessons from Lactococcus lactis and Escherichia coli. Trends Microbiol. 6: 214-216. r-51. Small, P., D. Blankenhorn., D. Welty., E. Zinser., and J.L. Slonczewski. 1994. Acid and base resistance in Escherichia coli and Shigella flexneri: role of rpoS and growth pH. J. Bacteriol. 176: 1729-1737.

r-52. Tosun, Halil., and Sahika A. Gonul. 2005. The Effect of Acid Adaptation Conditions on Acid Tolerance Response of Escherichia coliO157: H7. Turk J. Biol. 29: 197-202.

r-53. Tramonti, A.V.P., De-Canio, M., Falconi, M., and DeBiase, D. 2002. Functional characterization and regulation of gadX, a gene encoding an AraC/XylS-like transcriptional activator of the Escherichia coli glutamic acid decarboxylase system. J. Bacteriol 184: 2603-2613.

r-54. Waterman, Scott R., and P.L.C. Small. 2003.

Transcriptional Expression of Escherichia coli GlutamateDependent Acid Resistance Genes gadA and gadBC in an hns rpoS Mutant. . J. Bacteriol. 185: 4644-4647.

r-55. West, A.H., and A.M. Stock. 2001. Histidine kinases andresponse regulator proteins in two-component signaling systems. Trends in Biochemical Science. 26: 369-376. r-56. Yoshida, T., T. Yamashino., C. Ueguchi., and T. Mizuno. 1993. Expression of the Escherichia coli dimorphic glutamic acid decarboxylases is regulated by the nucleoid protein H-NS. Biosci. Biotech. Biochem. 57: 1568-1569. r-57. Yuk, Hyun-Gyun., and D.L. Marshall. 2004.

Adaptation of Escherichia coli O157:H7 to pH Alters Membrane Lipid Composition, Verotoxin Secretion, and Resistance to Simulated Gastric Fluid Acid. Appl. Environ. Microbiol. 70: 3500-3505. 


\section{Author Information}

Pradeep Jain

Post Graduate, Institute of Science, Nirma University, Ahmedabad, Gujarat, India

Sarika Sinha, PhD

Institute of Science, Nirma University, Ahmedabad, Gujarat, India 